\title{
Effect of positive/negative electrode ratio on cold metal transfer welding of 6061 aluminum alloy
}

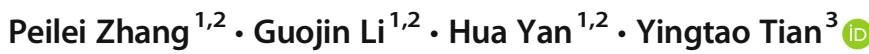

Received: 5 September 2019 / Accepted: 12 November 2019 / Published online: 17 December 2019

(C) The Author(s) 2019

\begin{abstract}
Variable polarity cold metal transfer (VPCMT) is a newly developed welding process and has drawn extensive interests because of its potential in further reducing the heat input, offering greater gap bridging ability, and improving the deposition rate. Using 6061 aluminum alloy as an example, this paper systematically investigated the influences of the key parameter in VPCMT, i.e., "positive/negative electrodes ratio (EP/EN Balance)," on weld formation, microstructure, and mechanical properties. It was found that, with the increase of the EP/EN Balance value, the duty cycle of the negative phase was reduced but the peak current and maximum temperature of the weld pool were both increased resulting in a higher heat input. The positive/negative electrode ratio had little impact on the grain misorientation angle in the fusion zone. Hardness of the joint was higher with larger positive duty cycles because of the precipitate phase and small grain size. An increased negative duty cycle resulted in lower heat input leading to insufficient melting of the material and deterioration of the mechanical strength of the welds.
\end{abstract}

Keywords Variable polarity cold metal transfer $\cdot$ Positive/negative electrode ratio $\cdot$ Aluminum welding process $\cdot$ Mechanical properties · Grain size

\section{Introduction}

In response to the low carbon emission target rectifying the climate change challenge, light weight structures are desired in aerospace, transportation, and many other industrial applications, where welded high strength $\mathrm{Al}$ structures are preferred due to its low density, high specific strength, and high structural integrity [1]. Cold metal transfer (CMT) has been widely applied for welding aluminum alloys due to its low heat input and excellent stability in terms of process control. Pickin and Young [2] found that the droplet transfer during CMT is rather different from other arc welding methods. The

Peilei Zhang

peilei@sues.edu.cn

Yingtao Tian

y.tian12@lancaster.ac.uk

1 School of Materials Engineering, Shanghai University of Engineering Science, Shanghai 201620, China

2 Shanghai Collaborative Innovation Center of Laser of Manufacturing Technology, Shanghai 201620, China

3 Department of Engineering, Lancaster University, Bailrigg, Lancaster LA1 4YW, UK direction of the wire movement would be reversed after contacting the welding pool. Key parameters affecting the microstructure, mechanical properties, and the welding quality include welding speed, peak current, short-circuiting time, and background time etc. which have been studied extensively in the past decade. For example, Heng Zhang et al. [3] used different welding speeds to study the microstructures of deposited AZ31 magnesium alloy clad. Large number of pores were observed in the fusion zone at a high welding speed. With the decrease of welding speed, the HAZ became more susceptible to liquation crackings. Wang et al. [4] found that increased short-circuit current resulted in larger grain size. Cao et al. [5] obtained a good brazed joint between aluminum and galvanized steel by carefully controlling the wire feed speed.

A new droplet transfer mode for CMT welding was recently developed by manipulating the ratio of positive/negative polarity, i.e., the so-called variable polarity cold metal transfer (VPCMT) advance $(\mathrm{C}+\mathrm{A})$ process [6], which offers greater gap bridging ability, even lower heat input and higher deposition rate. The positive/negative polarity would change in the short-circuit phase. Guojin Li et al. [7] were able to use the same parameters for different gap width and successfully achieved satisfactory mechanical strength in all weld joins 
Fig. 1 The schematic of welding experimental set-up

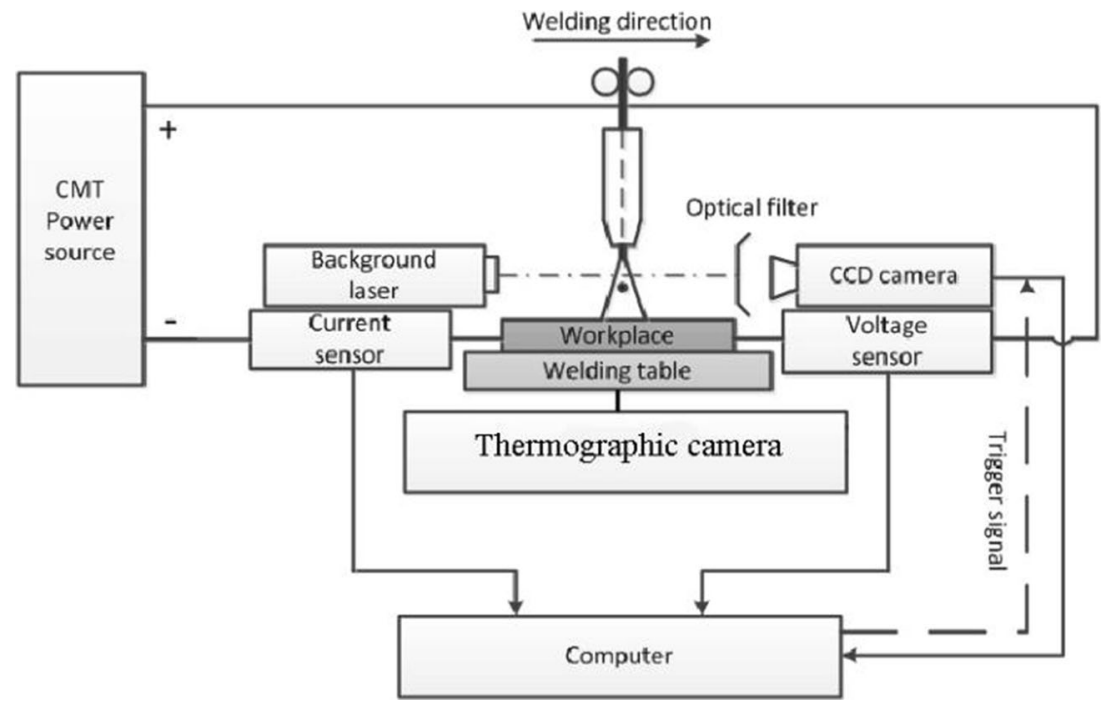

which demonstrated an excellent gap bridging ability through this VPCMT. Cong et al. [8] found that variable polarity cold metal transfer could reduce the porosity of weld seams with appropriate combination of parameter. Chen Zhang et al. [9] investigated the wire arc additive manufacturing of Al-6Mg alloy using variable polarity cold metal transfer. The variable polarity cold metal transfer had lower heat input and better deposition rate ability. During the welding process, there is a unique parameter called "EP/EN Balance" representing the electrode positive/negative ratio. Peng Wang et al. [10] used different electrode positive/negative ratio to weld $\mathrm{Mg} / \mathrm{Al}$ dissimilar welded joints and found that, with the increase of ENCMT-cycles, the energy input was lower and the strength of joints was higher. However, the influences of the electrode positive/negative ratio, i.e., "EP/EN balance," on the welding process and weld quality are still unclear and systematic study is therefore needed for the interest of both industry and academia.

This paper is to provide a further study on the influences of the "EP/EN Balance" parameter on welding process in terms of the weld formation, mechanical properties of the joints, and welding defects control. It is hoped that this study could provide further understanding of the variable polarity CMT and potentially be used as a technical guidance for people who
Table 2 Welding parameters for the experiment

\begin{tabular}{llllll}
\hline Specimen & 1 & 2 & 3 & 4 & 5 \\
\hline EP/EN Balance & -1 & -0.5 & 0 & 0.5 & 1 \\
WFS (m/min) & 5.5 & 5.5 & 5.5 & 5.5 & 5.5 \\
Welding speed (mm/s) & 10 & 10 & 10 & 10 & 10 \\
Arc length correction $(\%)$ & 0 & 0 & 0 & 0 & 0 \\
\hline
\end{tabular}

want to manipulate the CMT welding process and achieve a better welding quality.

\section{Experimental procedure}

As presented in Fig. 1, the experimental set-up could be divided into five parts: (1) welding system, which included a Transplus Synergic 4000 CMT power combined with ABB IRB 4600 robot; (2) oscilloscope system; (3) high-speed camera system with a frame rate of $5000 \mathrm{fps}$; (4) thermographic camera; and (5) industrial PC. The trigger signal was provided by the computer.

Table 1 Chemical composition of 6061 aluminum alloy and ER4043 filler metal

\begin{tabular}{llllllllll}
\hline Material & \multicolumn{2}{l}{ Mass fraction/\% } & & & & & & & \\
& \cline { 2 - 9 } & $\mathrm{Al}$ & $\mathrm{Mg}$ & $\mathrm{Si}$ & $\mathrm{Zn}$ & $\mathrm{Fe}$ & $\mathrm{Ti}$ & $\mathrm{Mn}$ & $\mathrm{Cu}$ \\
\hline $6061 \mathrm{Al}$ & Bal. & $0.6-1.2$ & $0.4-0.8$ & $\leq 0.5$ & $\leq 0.7$ & $\leq 0.15$ & $\leq 0.5$ & $0.15-0.4$ & $0.04-0.35$ \\
ER4043 & Bal. & $\leq 0.05$ & $4.5-6.0$ & $\leq 0.1$ & $\leq 0.8$ & $\leq 0.2$ & $\leq 0.05$ & $\leq 0.3$ & - \\
\hline
\end{tabular}




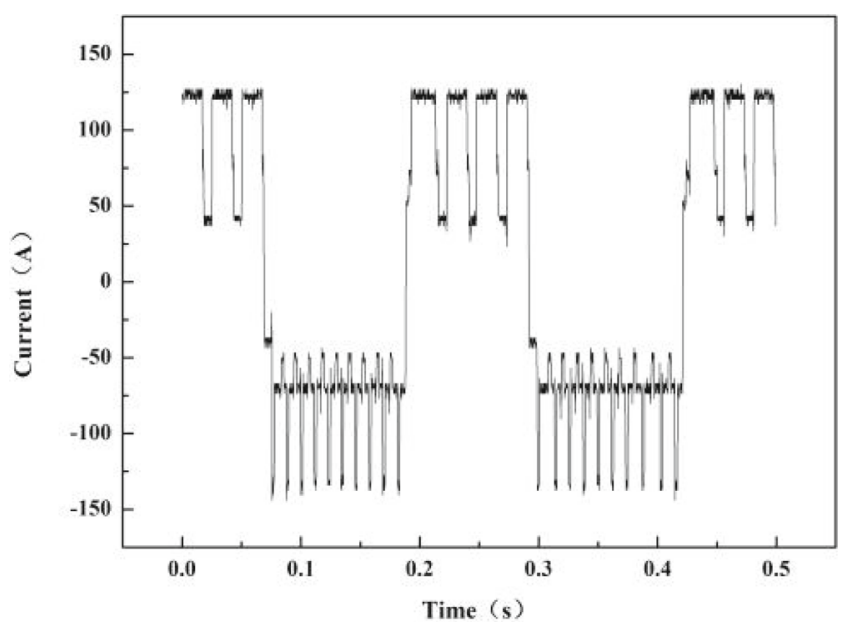

(a) EP/EN Balance=-1

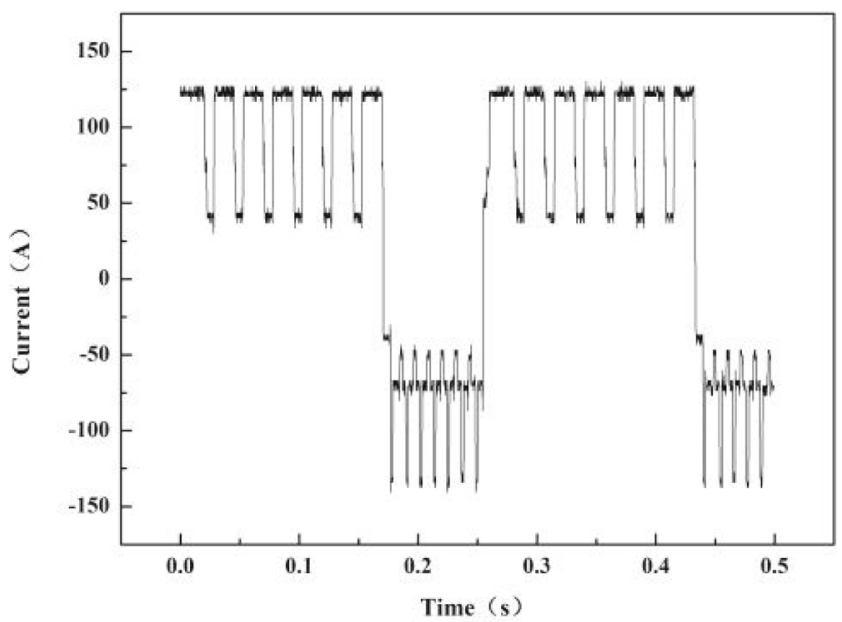

(c) $\mathrm{EP} / \mathrm{EN}$ Balance $=0$

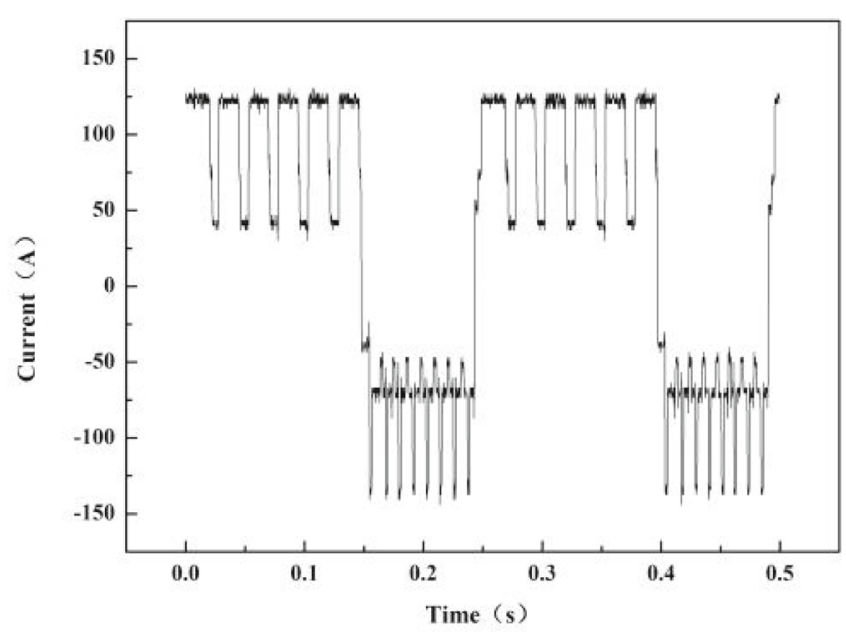

(b) $\mathrm{EP} / \mathrm{EN}$ Balance $=-0.5$

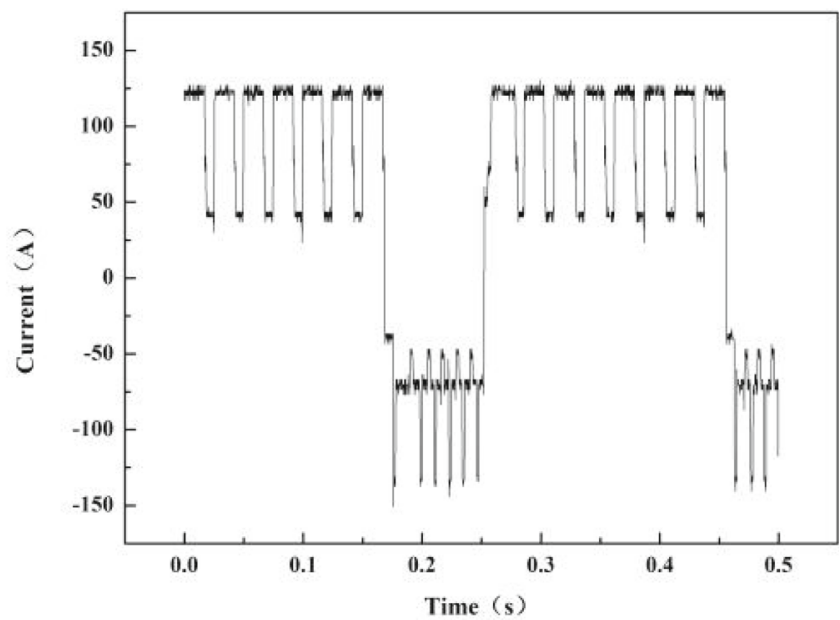

(d) EP/EN Balance $=0.5$

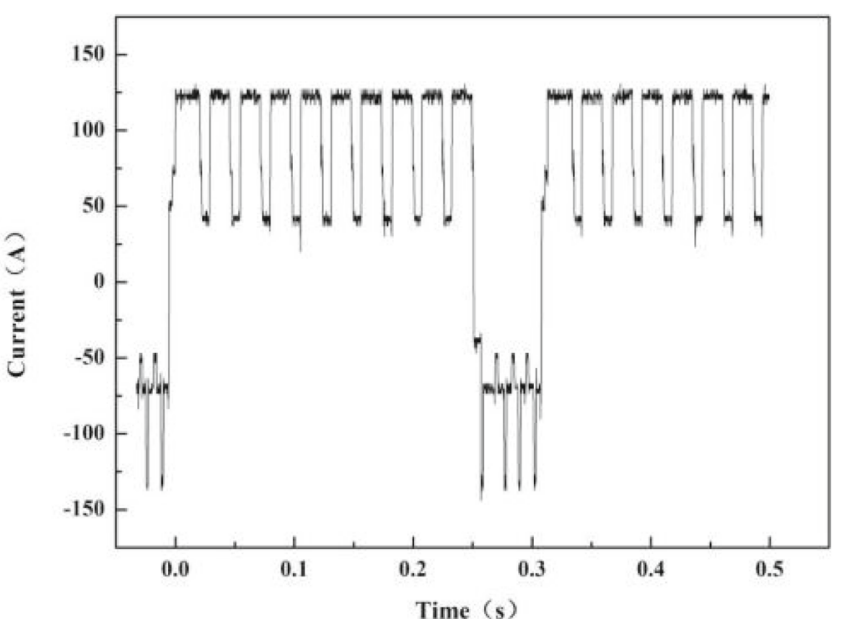

(e) $\mathrm{EP} / \mathrm{EN}$ Balance $=1$

Fig. 2 Current waveform for different EP/EN Balance values: (a) -1; (b) -0.5 ; (c) 0 ; (d) 0.5 and (e) 1 
Table 3 The relationship between EP/EN Balance and positive/ negative cycles

\begin{tabular}{cccccc}
\hline EP/EN Balance & -1 & -0.5 & 0 & 0.5 & 1 \\
Positive cycles & 4 & 6 & 7 & 8 & 10 \\
Negative cycles & 10 & 8 & 7 & 6 & 4 \\
Electrode positive/negative ratio & $2: 5$ & $3: 4$ & 1 & $4: 3$ & $5: 2$ \\
\hline
\end{tabular}

The testing system for the welding current/voltage acquisition consisted of an oscilloscope (DSOX4024A) and a current probe (N2780B). The frequency of droplet transfer could be extracted from the current waveform. The highspeed CCD camera was a Phantom VEO 640S (resolution: $1280 \times 600$ ) which was able to record the dynamic behavior of the arc and molten droplets. The interval time between every two successive photos was about $0.2 \mathrm{~ms}$. In addition, an FLIR A615 IR thermal imaging system was used to acquire the temperature signals. The infrared images of the molten pool were collected in real time by the IR thermal imaging system that were used to investigate

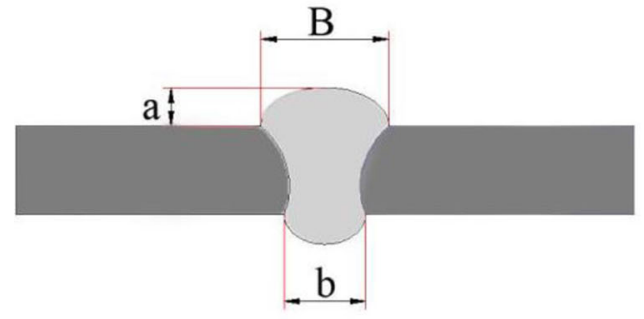

(a)

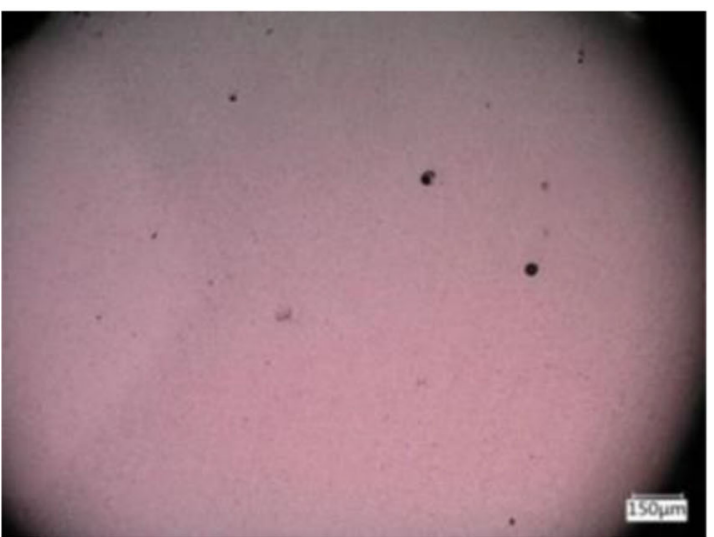

(c)

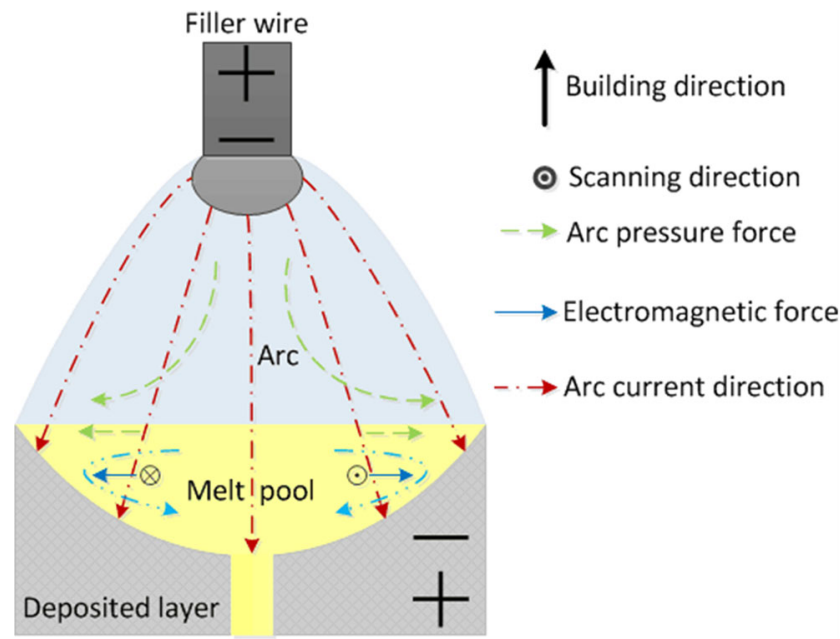

Fig. 4 The effects of variable polarity arc on the melting pool

the relationship between electrode positive/negative ratio and the temperature of the welding pool.

The dimensions of base metal (6061 aluminum alloy) were $150 \mathrm{~mm} \times 100 \mathrm{~mm} \times 2 \mathrm{~mm}$ and the filler metal was

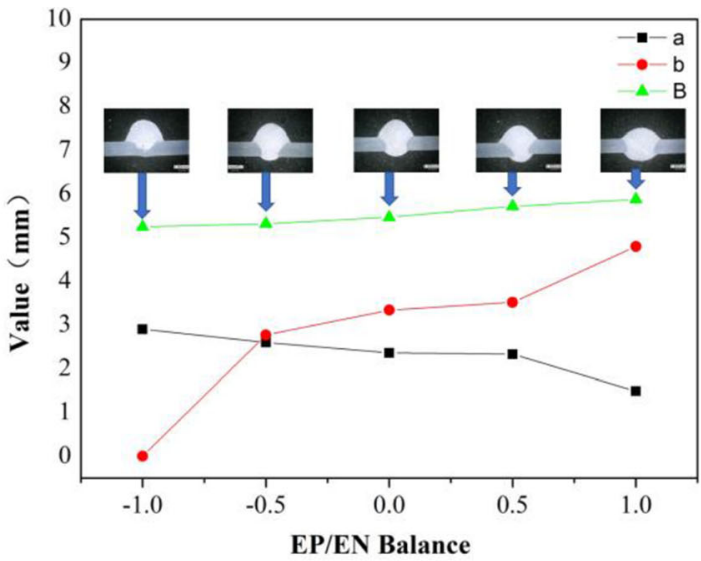

(b)

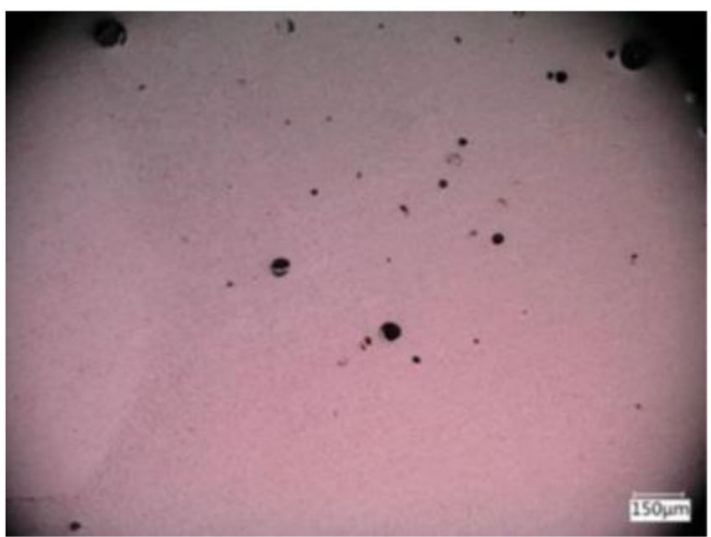

(d)

Fig. 3 Formation parameters of the joints. a Map of the joint. b Forming parameter of the joints. $\mathbf{c}$ More positive cycles. $\mathbf{d}$ More negative cycles 


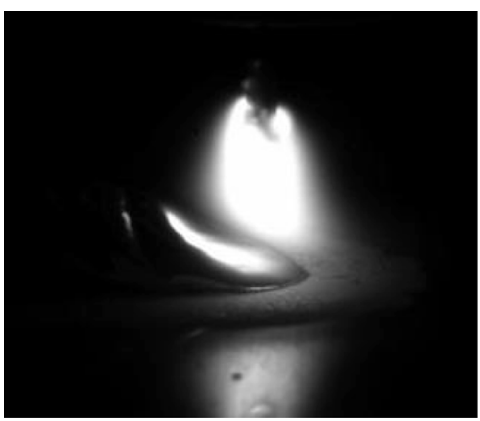

(a) $\mathrm{EP} / \mathrm{EN}=1(148 \mathrm{~A})$

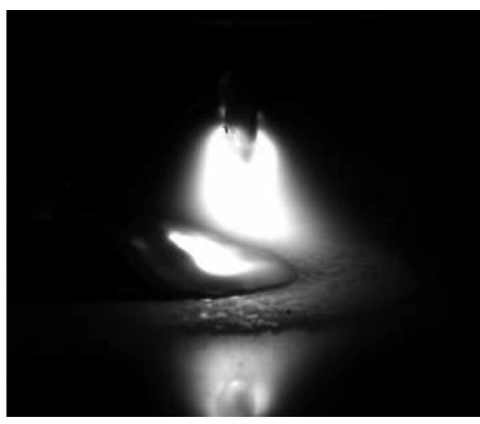

(b) $\mathrm{EP} / \mathrm{EN}=0(140 \mathrm{~A})$

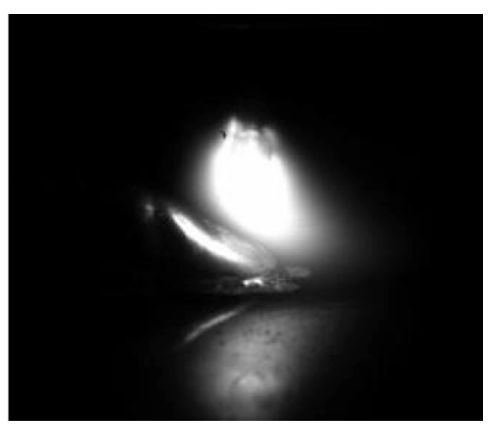

(c) $\mathrm{EP} / \mathrm{EN}=-1(135 \mathrm{~A})$

Fig. 5 The acquired arc images of negative cycle at different conditions: (a) $\mathrm{EP} / \mathrm{EN}=1(148 \mathrm{~A}) ;(\mathbf{b}) \mathrm{EP} / \mathrm{EN}=0(140 \mathrm{~A})$ and $(\mathbf{c}) \mathrm{EP} / \mathrm{EN}=-1(135 \mathrm{~A})$

ER4043 with a diameter of $1.2 \mathrm{~mm}$. The chemical composition of the base metal and filler metal was given in Table 1. Pure argon (99\%) was employed as shielding gas and the flow rate was $21 \mathrm{~L} / \mathrm{min}$ and the distance from tip to workpiece was kept at $12 \mathrm{~mm}$. The other welding parameters were listed in Table 2. After welding, the crosssections of the joints were investigated to reveal the geometry of the welds, microstructures, and welding defects by using a VHX-5000 optical microscope (OM). Electron back-scattered diffraction (EBSD) was then adopted to analyze the grain structure of transverse cross-sections in fusion zone. The tensile test specimens were prepared according to GB2651-2008 standard and tested by using an AG-25TA tensile machine with a load rate of $2 \mathrm{~mm} / \mathrm{min}$. The fracture morphology was observed in an S-3400N scanning electron microscope (SEM) to study the effects of electrode positive/negative ratio on the mechanical strength of welded joints. In addition, a HDX-1000 automatic Vickers microhardness tester was employed to evaluate microhardness in the joint.

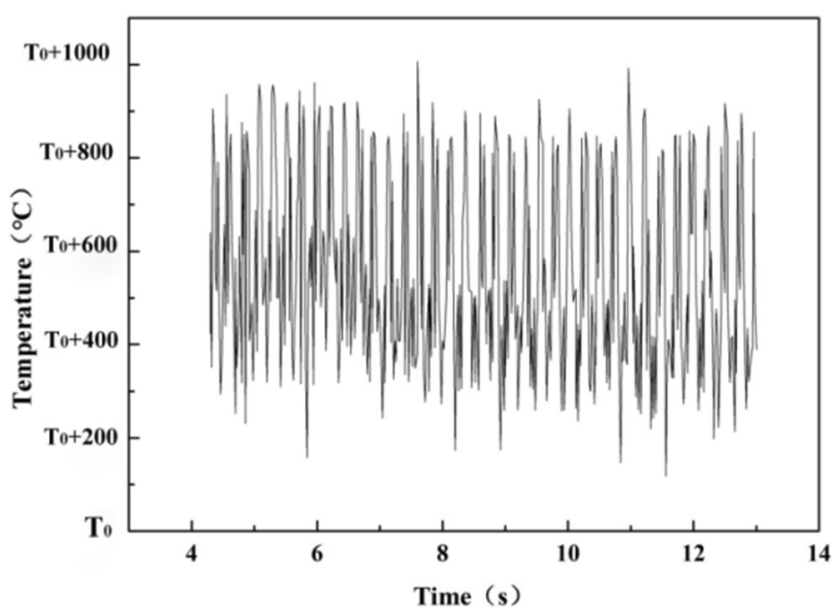

Fig. 6 The waveform of max temperature for the molten metals (EP/EN Balance $=-1)$

\section{Results and discussion}

\subsection{The current waveforms}

The current waveforms for different EP/EN Balance values are shown in Fig. 2. The electrode positive/negative ratio varied corresponding to different EP/EN Balance values. The relationship between EP/EN Balance values and positive/negative cycles is shown in Table 3. The positive polarity cycle could be divided into three phases. At first, the current increased immediately when the droplet separated from the welding pool, and then the current kept nearly unchanged when the droplet increased in size. After that, the current dropped down in the shortcircuiting phase. For the negative polarity, there were also three phases in one cycle similar to the positive polarity.

When the EP/EN Balance value was very low $(<0)$, the deposition ability became greater and the heat input decreased correspondingly. When the EP/EN Balance values became higher $(>0)$, the heat input would therefore increase while the deposition ability deteriorated. When the electrode positive/negative ratio changed, the peak value of the positive current was nearly the same $(125 \mathrm{~A})$. The frequency of droplet transfer increased with the decreasing of the electrode positive/negative ratio. It varied from 3.234 to $4.558 \mathrm{~Hz}$ when the EP/EN Balance values changed from 1 to -1 and the period of EP-CMT-cycle was longer than EN-CMT-cycle. In addition, the time of droplet transfer was mainly affected by the plasma drag force $F_{\mathrm{p}}$ [11]:

$F_{\mathrm{p}}=K I^{2}$

where $K$ was the coefficient related to the distribution of arc, $I$ was the current value. The formation of the force was because that the plasma moved from the tip of wire to the work piece. The droplet could drop off more easily when the plasma force was larger. 
Fig. 7 The shape variation of arc and welding pools during the welding process $(\mathrm{EP} / \mathrm{EN}$ Balance $=-1$ )

Fig. 8 The infrared image of the welding pool
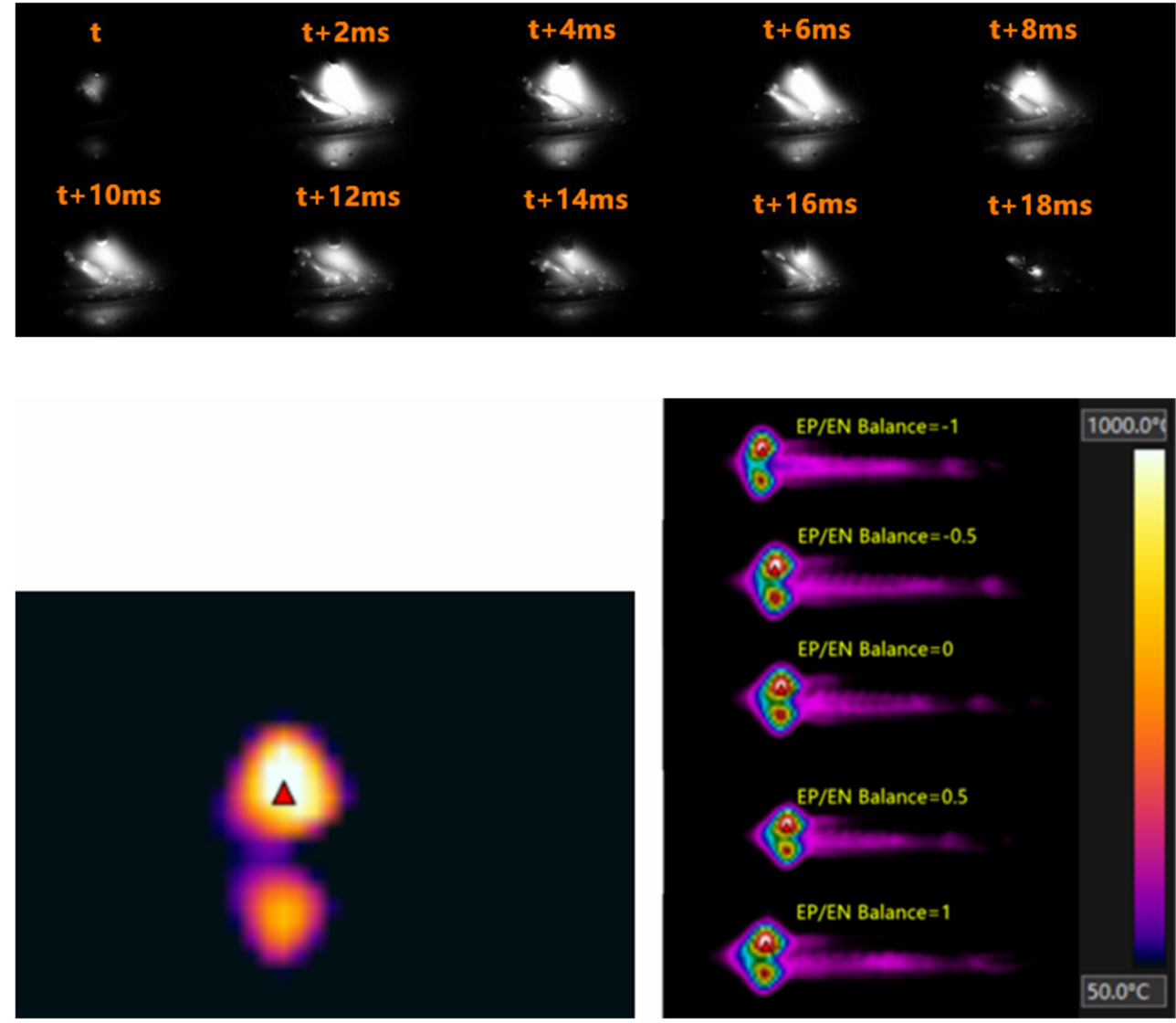

\subsection{Weld bead formation}

Figure 3 presents the cross-sections and geometric dimensions of welded joints. The positive/negative electrode ratio had significant influences on the weld formation. When the EP/EN Balance value was very low, the heat input was not enough to melt the base metal so that the depth of weld penetration was relatively shallow. Due to a lower heat input, the filling metals were all cladding on the surface of the work plates leading to larger weld reinforcement. As the positive cycles increased, the heat input would become higher to change the welding bead appearance. The front/ back of weld width became bigger while the reinforcement became smaller. Additionally, the wetting angle was also different under the variation of EP/EN Balance values, i.e., the wetting angle was smaller with more positive cycles. The experimental results further revealed that there were more gas pores in the welded joints when there were much more negative cycles than the positive ones, as shown in Fig. 3c, d.

\subsection{Arc behavior and droplet size}

The adjustment of EP/EN Balance value could affect the weld current and voltage. Figure 4 shows the effect of variable polarity arc on the molten pool. The forces acting

\section{EP/EN Balance from 1 to -1}
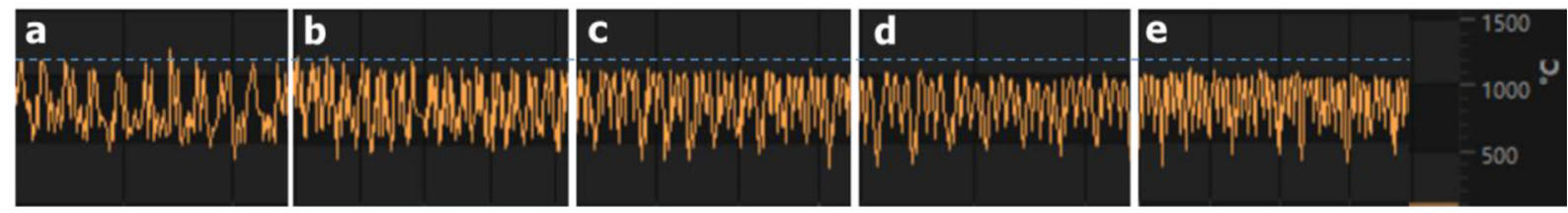

Fig. 9 The max temperature waveforms under different EP/EN Balance values: (a) 1; (b) 0.5; (c) 0; (d) -0.5 and (e) -1 

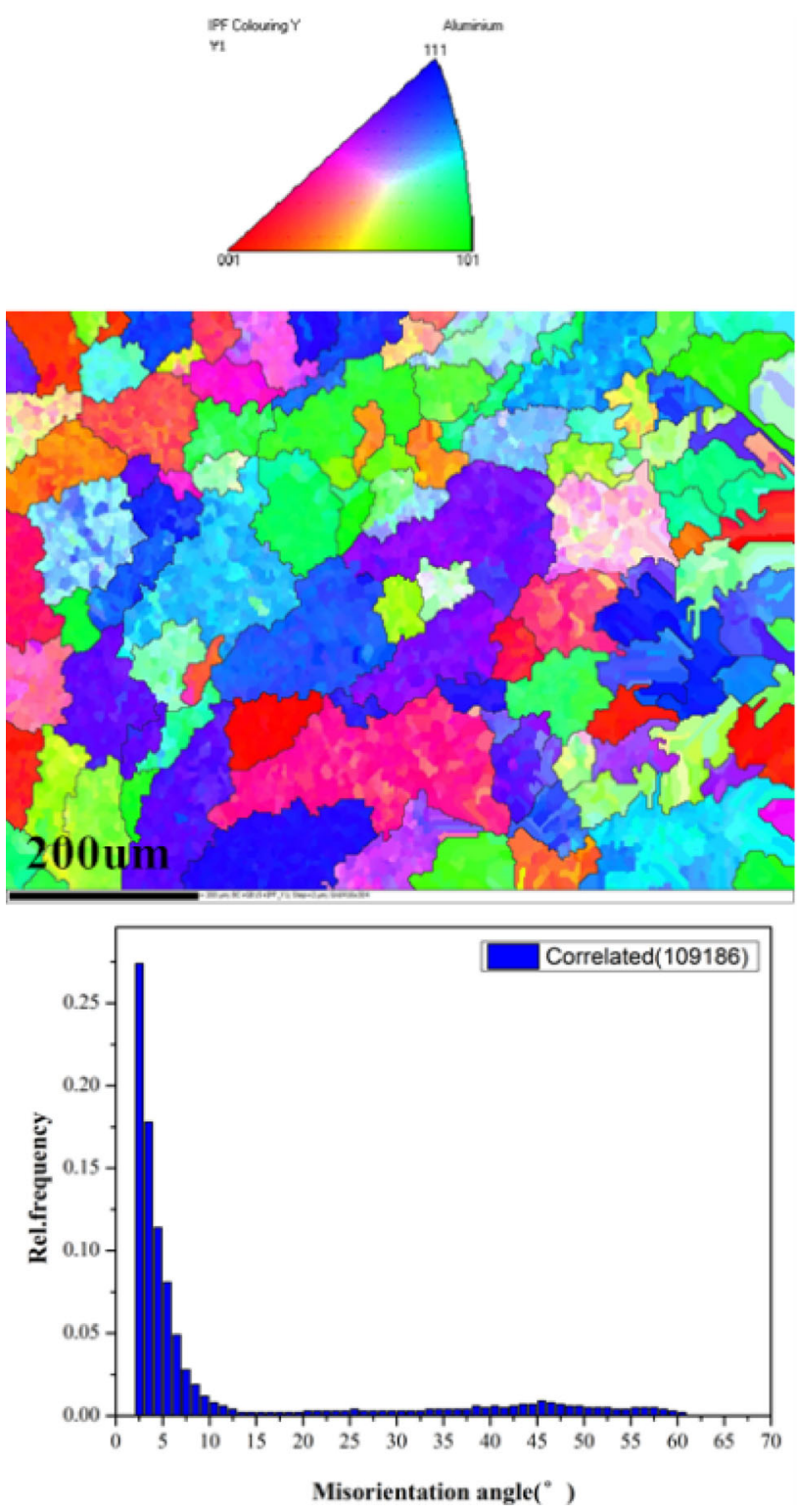

(a) EP/EN Balance=-1
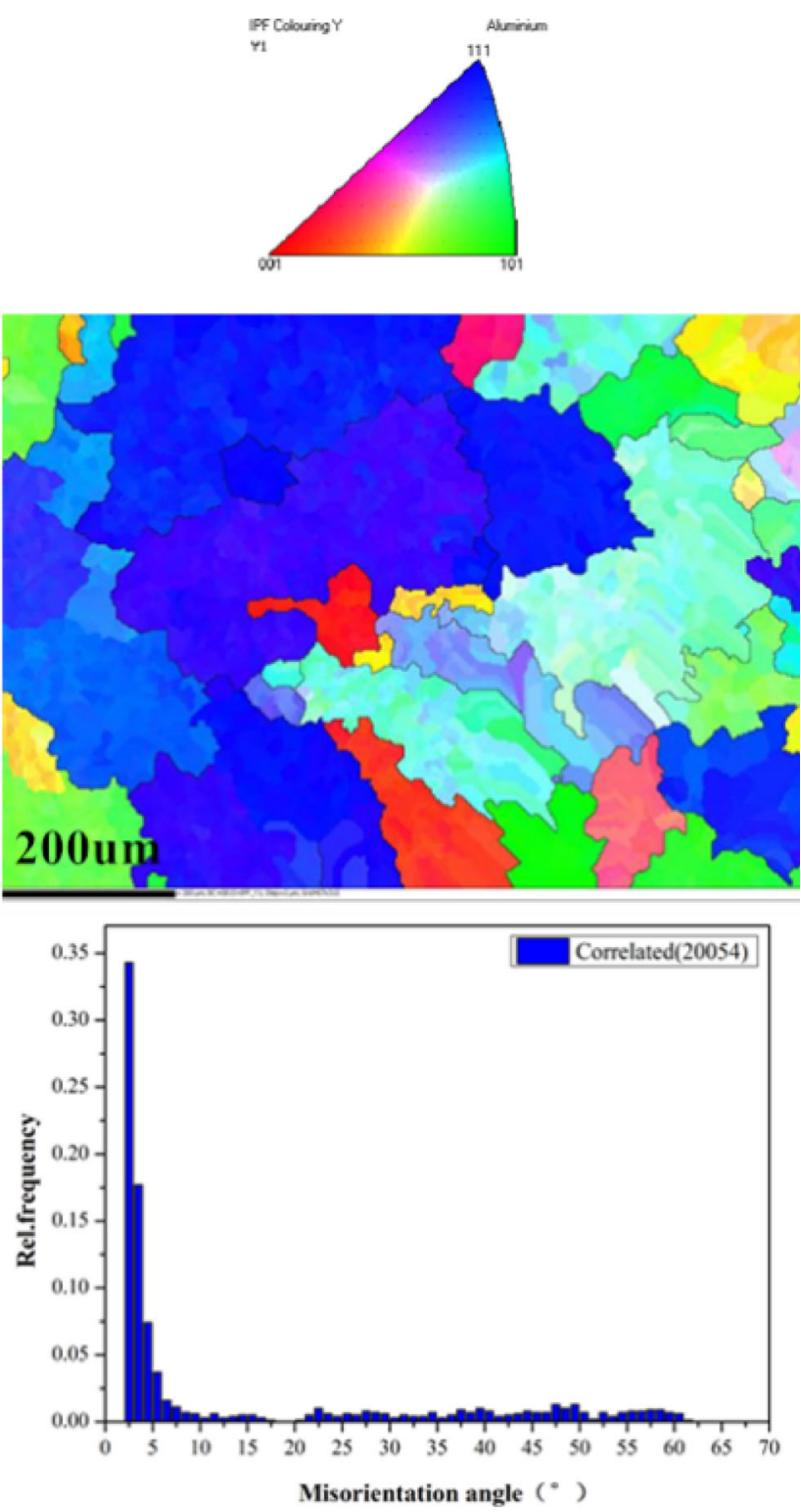

(b) EP/EN Balance $=1$

Fig. 10 EBSD IPF maps and statistics charts of misorientation angle on transverse cross-section of different EP/EN Balance values: (a) -1 and (b) 1

on the arc included the electromagnetic force, plasma drag force, and spot pressure and the major force determining the weld arc shape was the electromagnetic force $F_{1}$ :

$F_{1}=\frac{\mu}{4 \pi} I^{2} \ln \left(\frac{R_{b}}{R_{a}}\right)$

where $R_{\mathrm{a}}$ and $R_{\mathrm{b}}$ were the upper radius and bottom radius of the arc column respectively and $\mu$ was the magnetic conductivity. With the increase of weld current, the electromagnetic force would become larger resulting in an expanded width of the arc column. Figure 5 presents morphologies of the arc during negative cycles at different EP/ EN Balance values. The current corresponding to the three figures were $148 \mathrm{~A}, 140 \mathrm{~A}$, and $135 \mathrm{~A}$, respectively. The peak current of negative cycle increased as the EP/EN Balance value became greater.

The droplet behavior prior contacting the weld pool in short-circuiting transfer was observed by the high-speed video. The droplet would detach from the wire tip by retracting the filler wire. The adjustment of positive/ negative electrode ratio had little impact on the droplet size. Maoai Chen et al. [12] found that the droplet size 


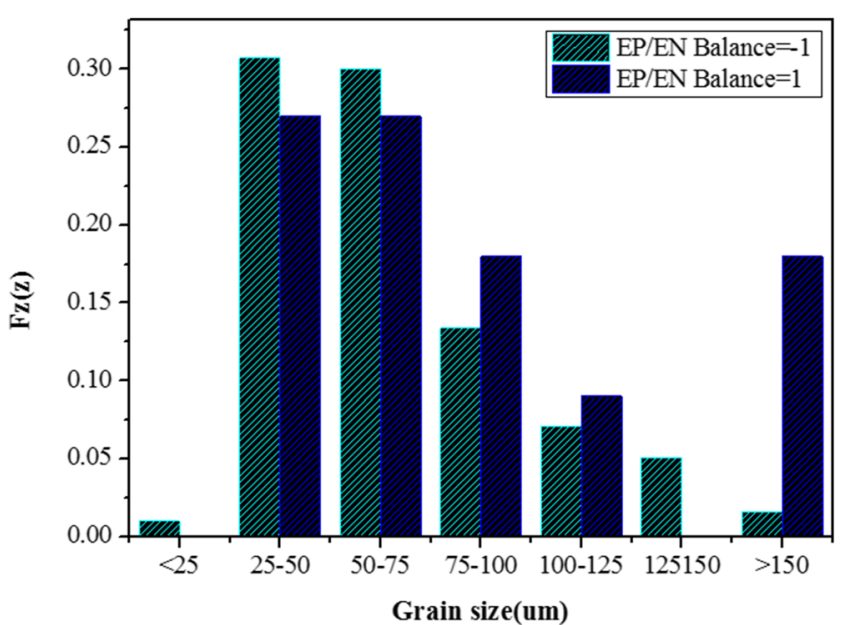

Fig. 11 A chart representing the grain size distribution under different $\mathrm{EP} / \mathrm{EN}$ Balance values

increases with an increase in the boost current. Due to the same peak current, the droplet size during positive cycle remained unchanged. The peak current of negative cycle increased when the EP/EN Balance increased. However, the difference in current was very small so that the droplet size was nearly the same when the polarity switched to negative phase. Guojin Li et al. [7] have calculated the droplet size of different polarity and obtained a relationship between different polarities, that is: $V_{\mathrm{cp}}=1.024 V_{\mathrm{c}}$, $V_{\mathrm{cn}}=1.65 V_{\mathrm{c}}$, where $V_{\mathrm{c}}$ is the volume for CMT mode, $V_{\mathrm{cn}}$ is the volume for negative phase, and $V_{\mathrm{cp}}$ is the volume of droplet for positive phase. The droplet size during negative cycle was larger than the size during positive phase. This was mainly because that the positive ions in the arc had a greater impact on the droplet, which revealed that more heat input was used to melt the wire for the negative cycle to improve the deposition rate.

\subsubsection{Effect on infrared imaging}

The formula governing the intensity of emitted radiation according to the absolute temperature was known as Planck's law [13]:

$E_{T}=\varepsilon \sigma^{*} T_{4}$

where $E_{T}$ was the irradiance, $\sigma$ was the Stefan-Boltzmann constant, $T$ was the thermodynamic temperature, and $\varepsilon$ was the emissivity of the material surface. The infrared images were captured for investigating the influence of EP/EN Balance on the weld appearance. As can be seen in Fig. 6 , the temperature repeatedly changed during the welding process because the wire was melted by the weld arc in a repetitive manner. Figure 7 further shows the behavioral evolution of arc and welding pools within a period in the VPCMT welding process. In the phase of arc striking or extinguishing, the temperature of the arc was lower and less energy was transferred to the filler wire resulting in a "cold" droplet. On the contrary, when the arc became brighter, more energy can be used to heat the metal wire leading to a higher temperature in the droplet.

The temperature distribution of the welding pools was displayed in Fig. 8. The rear part of the welding pool continued to receive the molten metal and the bead was continuously solidified. The highest part was the droplet heated by the arc and the other half was the melt pool. Figure 9 illustrates the maximum temperatures under different EP/ EN Balance values. The maximum temperature increased significantly when the positive cycles increased inducing a higher heat input. When the EP/EN Balance was at its smallest value, i.e., -1 , the temperature was the lowest and the heat input was not enough to melt the work plate.

\subsection{Grain size and crystal orientation}

EBSD analysis was carried out at the center of the fusion zone and HAZ of transverse cross-sections for two samples. The majority of the fusion zone contained equiaxed grains. The formation of equiaxed grains was mainly because of the arc swinging and arc pulsation. There are seldom any columnar grains because of the use of cold metal transfer arc mode with periodic changes of polarity.

Grain boundaries distinguished as high-angle $\left(\geq 15^{\circ}\right)$ ones were marked with black lines, while low-angle $\left(2^{\circ}-\right.$ $15^{\circ}$ ) grain boundaries were marked with white lines. Grain maps and the distribution of misorientation angle under different EP/EN Balance values were shown in Fig. 10. The misorientation angle distribution concentrating in small angle $\left(2.5^{\circ}-10^{\circ}\right)$ was in similar pattern in both samples. It showed that the positive/negative electrode ratio had little effect on the misorientation. Figure 11 shows the distribution of grain sizes in the two samples. It was clearly seen that the average grain size became larger in the case of more cycles that were positive. When the negative cycle was much less than the positive ones, the grain size was between 25 and $100 \mu \mathrm{m}$.

Figure 12 further shows the grain maps and the distribution of misorientation angle in different regions (fusion zone and HAZ). The misorientation angle in majority of the fusion zone was rather small, i.e., varying from $2.5^{\circ}$ to $15^{\circ}$, while the misorientation angle in $\mathrm{HAZ}$ was relatively larger, i.e., varied from $2.5^{\circ}$ to $60^{\circ}$. Figure 13 also shows that the grain size was scattered in different regions and the average grain size in fusion zone $(>100 \mu \mathrm{m})$ was much larger than that of HAZ $(0-50 \mu \mathrm{m})$. The difference in grain 

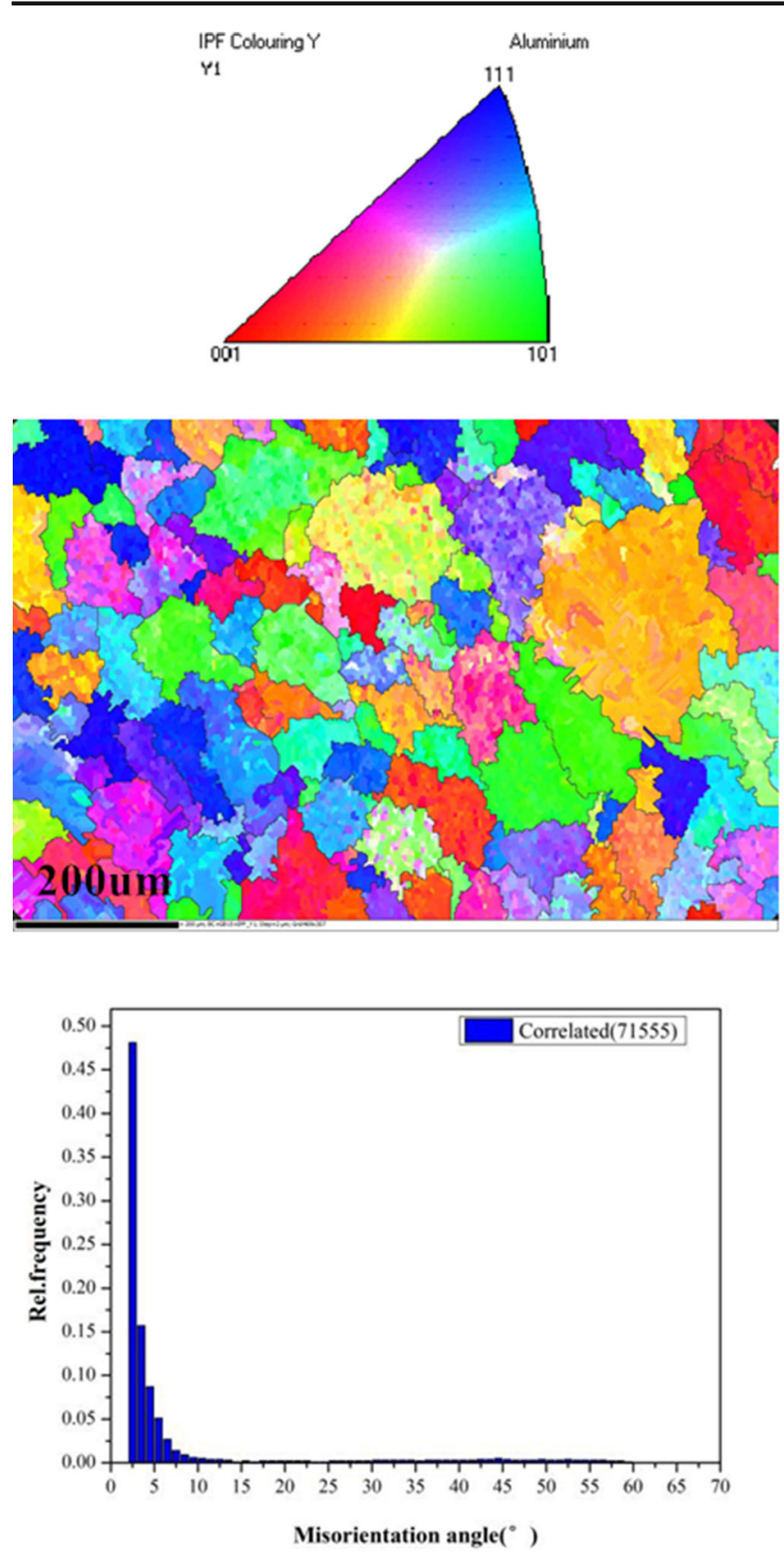

(a) The region in fusion zone
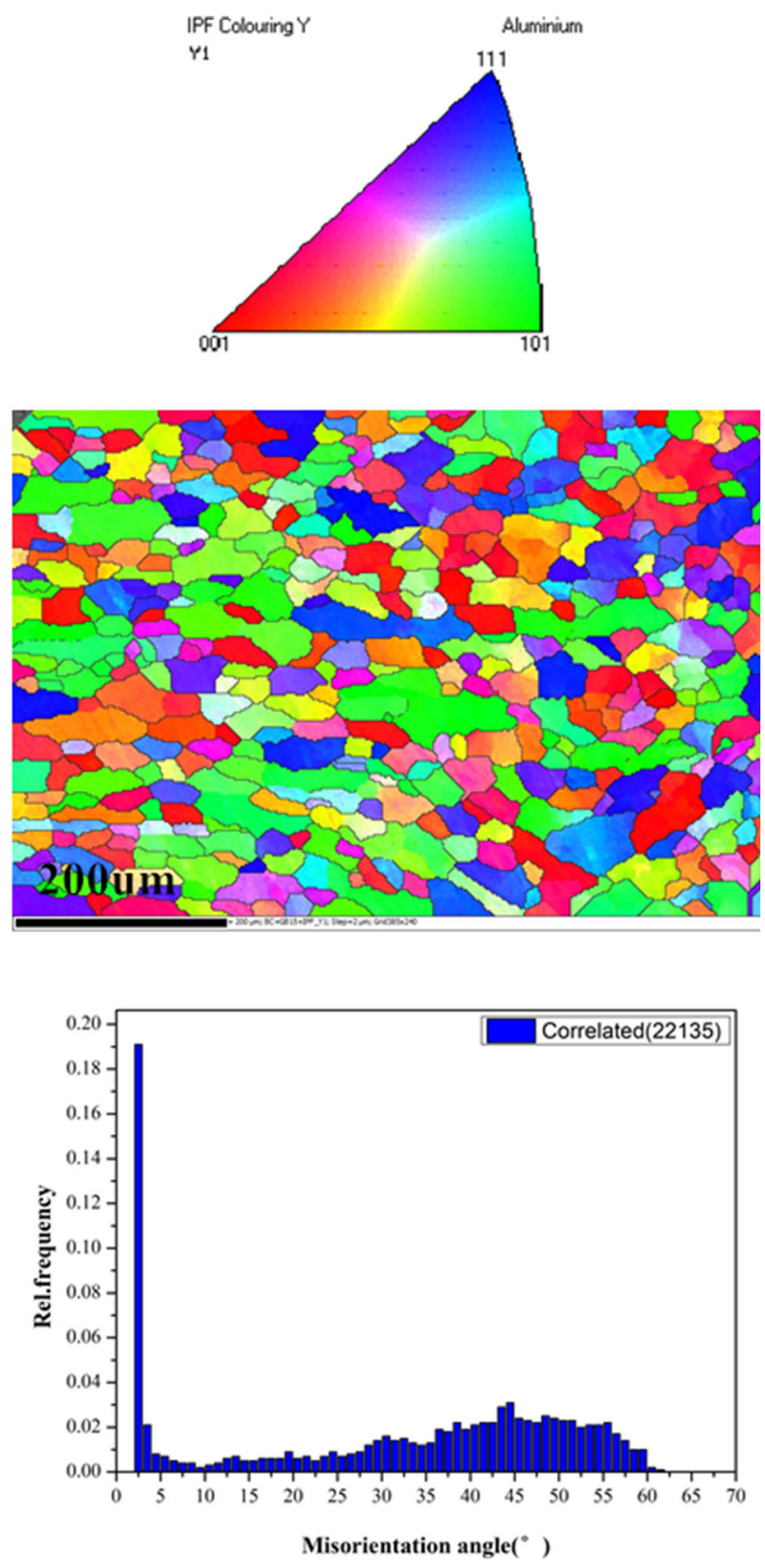

(b) The region in HAZ

Fig. 12 EBSD IPF maps and statistics charts of misorientation angle on transverse cross-section of different regions $(\mathrm{EP} / \mathrm{EN}$ Balance $=-1)$ : (a) the region in fusion zone; and (b) the region in HAZ)

sizes would provide a good explanation for the hardness variation in the two regions.

\subsection{Mechanical properties}

Figure 14 displays the measurement results of microhardness distributions along the left, middle, and right of the joints. The microhardness test points were taken at $0.2 \mathrm{~mm}$ step size on across the welded joints. The hardness of heat affected zone (HAZ) was higher than other regions regardless of the positive/negative electrode ratio, where the metal was strengthened by the solid solution. Precipitation hardening had less impact due to the fast cooling rate where the precipitates did not have sufficient time to nucleate. Figure 12 shows that the grain size of HAZ was smaller than other regions so that the hardness was relatively higher. The hardness of the fusion zone was very low due to grain coarsening effect. When the EP/EN Balance 


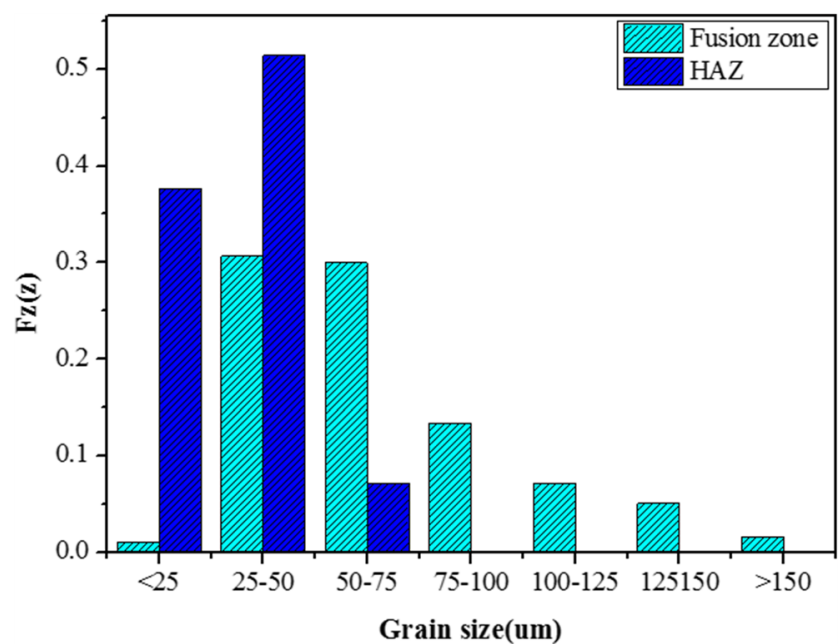

Fig. 13 A chart representing the grain size distribution in different regions

value was the smallest, the hardness of the welded joints was relatively small due to a lower heat input. When the $\mathrm{EP} / \mathrm{EN}$ Balance value was higher (from 0 to 1), it provided a greater possibility for the nucleation of precipitates, then the hardness of HAZ was greater than the fusion zone and base metals. As a result, the fracture did not take place in the heat affected zone.

The sketch map of a tensile sample was shown in Fig. 15a. The joints had two different fracture conditions. When the EP/EN Balance value was lower (from -1 to 0.5 ), the fracture took place in the welding seam. When the $\mathrm{EP} / \mathrm{EN}$ Balance value increased (from 0 to 1), the fracture took place in the base metals. The main reason for this phenomenon was that the strengthening by grain size reduction in the HAZ. The tensile strength increased first and then slightly decreased. When the EP/EN Balance was the

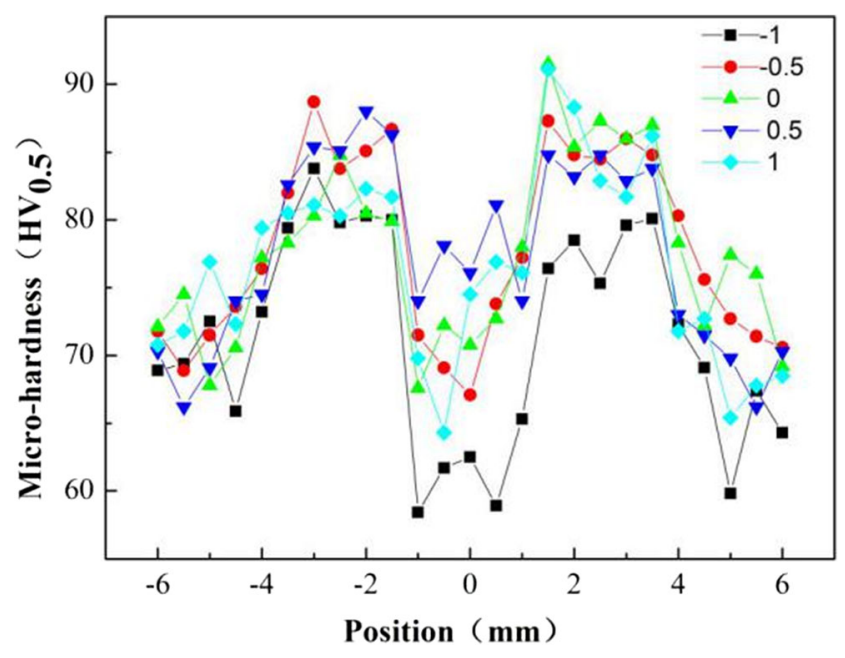

Fig. 14 Microhardness of the joints at different EP/EN Balance values smallest, the work plate was not completely melted and the depth of weld penetration was low so that the tensile strength became much lower. When the EP/EN Balance value was -0.5 , the strength was still not very high. When the EP/EN Balance value further increased, the heat input was enough to melt the work plate and the tensile strength was relatively high. The difference of tensile strength between several samples was very small. The strength was not affected despite the root became obviously bigger when the electrode positive/negative ratio increased. The root has little effect on the tensile strength of the welded joints.

The fracture surface was observed by using scanning electron microscopy (SEM). Figure 16 shows the fracture morphology of joints under different EP/EN Balance values. Figure 16 a shows the fracture morphology in the case of maximum negative cycle. Gas pores can be observed in the fusion zone due to the low heat input on the welding process. Additionally, there were also many tearing ridges around the pore. Haobo Liu et al. [14] found that vast number of tearing ridges indicates that there was more than one initiation near the pore. Frost et al. [15] investigated fatigue initiation without propagation, and found that microcracks can initiate near weld pores, even under low level of cyclic stress. The existence of pores and cracks would affect the strength of the joints. When the EP/EN Balance values increased to -0.5 , the heat input became higher but the fracture still took place in the welding seam. Figure $16 \mathrm{c}$ and $\mathrm{d}$ show the fracture morphologies of the weld reinforcement and root respectively. In region 1 , the fracture mode of the alloys was cleavage fracture with river pattern. In region 2, it was belong to brittle fracture with step pattern. When the EP/EN Balance values were larger (from 0 to 1), the fracture took place in the base metals and the failure exhibited a ductile mode. A large number dimples can be observed on the fracture surface but no pores were spotted which explained the high strength of the joint.

\section{Conclusions}

1. The variety of positive/negative electrode ratio would affect the current waveform. The peak value of the negative current became lower with the decrease of the positive/ negative electrode ratio, while the peak current of positive cycle kept unchanged. The time of droplet transfer for positive cycle was longer due to the lower plasma drag force.

2. The arc length for negative cycle was longer with the increase of the EP/EN Balance value. The maximum temperature of welding pool increased with a larger proportion of positive cycles according to the infrared images which would affect the weld formation. 


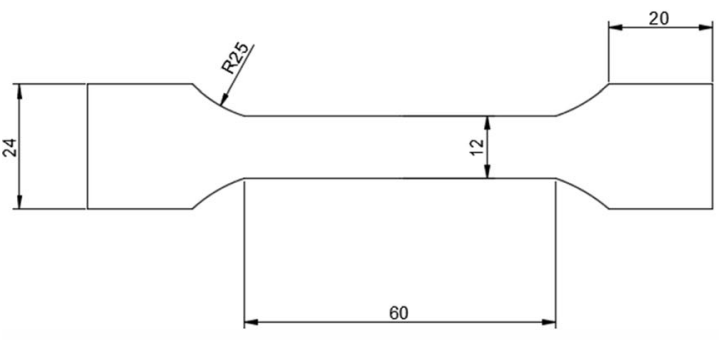

(a)

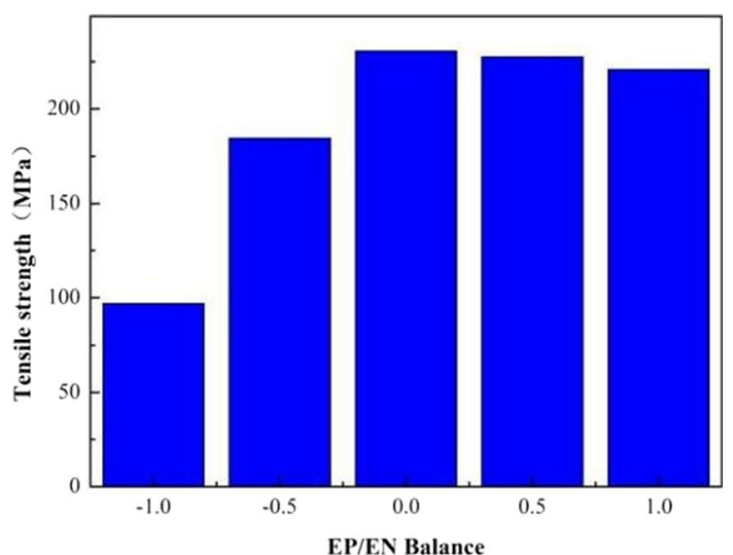

(b)

Fig. 15 Tensile testing of different joints. a Sketch map of tensile sample. b Tensile strength

3. The grain size was larger with increased positive duty cycles because of the higher heat input. The HAZ exhibited a smaller grain size but a larger misorientation angle comparing with the fusion zone.

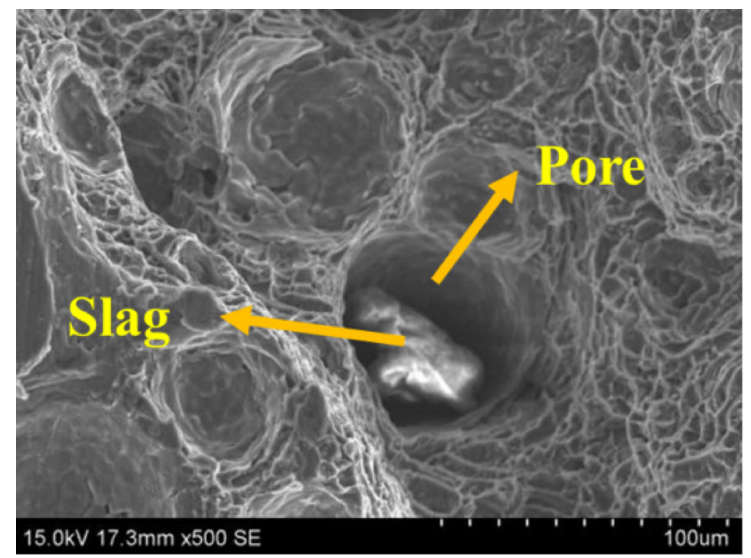

(a) EP/EN Balance value $=-1$

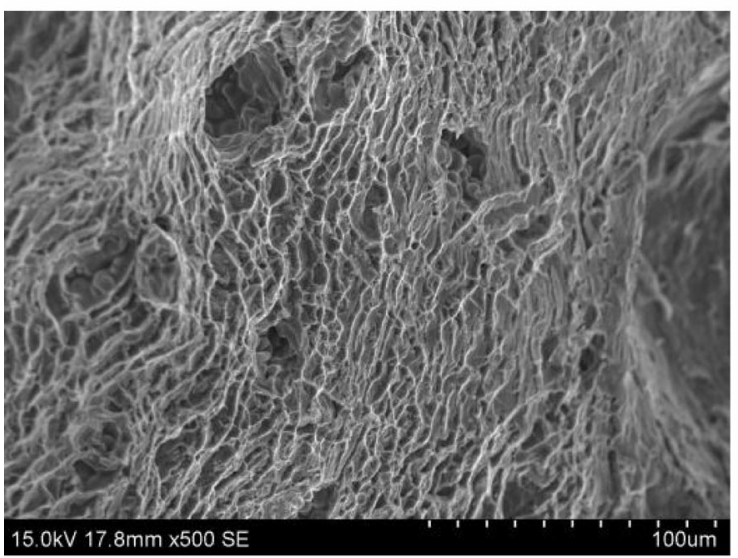

(c) EP/EN Balance value $=-0.5$ (region 1$)$
4. By increasing the positive duty cycles, the microhardness in both HAZ and fusion zone were increased correspondingly. The tensile strength of the welded joints increased first but then slightly decreased when

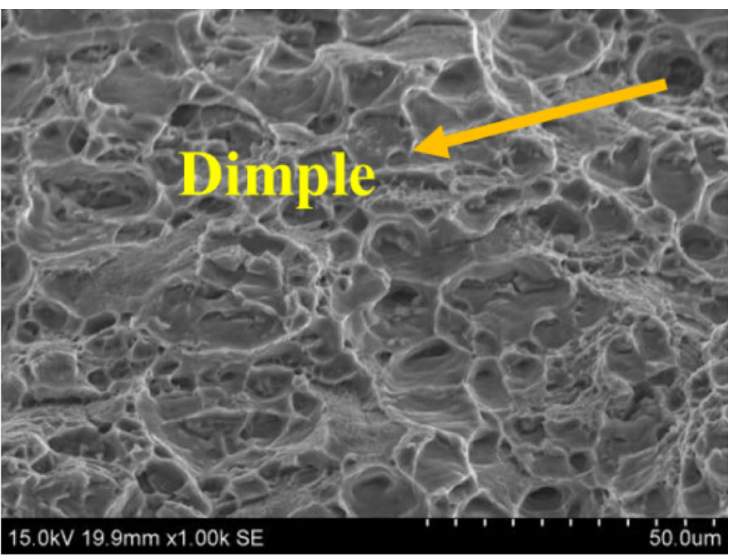

(b) $\mathrm{EP} / \mathrm{EN}$ Balance value $=0$

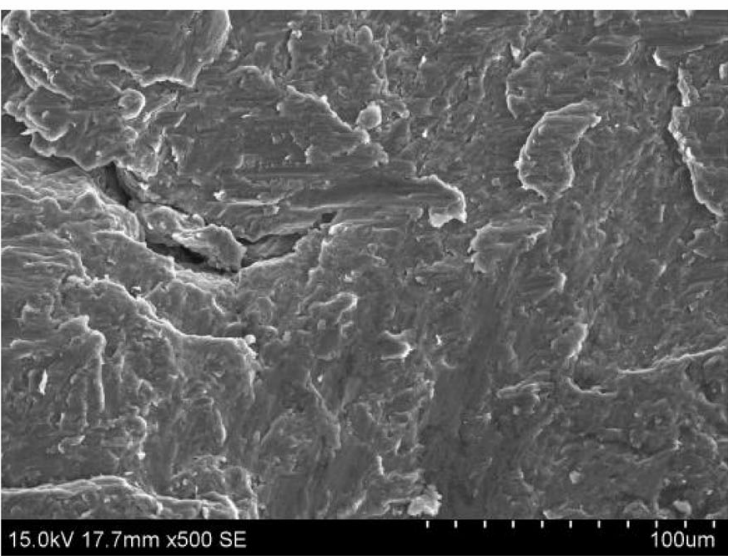

(d) EP/EN Balance value $=-0.5$ (region 2)

Fig. 16 Fracture morphology of joints at different conditions: (a) $\mathrm{EP} / \mathrm{EN}=-1 ;(\mathbf{b}) \mathrm{EP} / \mathrm{EN}=0$; (c) $\mathrm{EP} / \mathrm{EN}=-0.5$ (region 1); and (d) $\mathrm{EP} / \mathrm{EN}=-0.5$ (region 2) 
the positive duty cycle exceeded certain level. Some holes on the fracture surface could easily be formed with the fewer positive cycle due to the lower heat input.

Acknowledgments This research was supported by the Natural Science Foundation of China (51605276, 51905333), Shanghai Sailing Program (19YF1418100), Shanghai Science and Technology Committee Innovation Grant (17JC1400600, 17JC1400601), Karamay Science and Technology Major Project (2018ZD002B), Aid for Xinjiang Science and Technology Project (2019E0235), and Shanghai local colleges and universities capacity building special plan project (19030501300).

Open Access This article is licensed under a Creative Commons Attribution 4.0 International License, which permits use, sharing, adaptation, distribution and reproduction in any medium or format, as long as you give appropriate credit to the original author(s) and the source, provide a link to the Creative Commons licence, and indicate if changes were made. The images or other third party material in this article are included in the article's Creative Commons licence, unless indicated otherwise in a credit line to the material. If material is not included in the article's Creative Commons licence and your intended use is not permitted by statutory regulation or exceeds the permitted use, you will need to obtain permission directly from the copyright holder. To view a copy of this licence, visit http://creativecommons.org/licenses/by/4.0/.

\section{References}

1. Yan S, Xing B, Zhou H, Xiao Y, Qin Q-H, Chen H (2018) Effect of filling materials on the microstructure and properties of hybrid laser welded Al-Mg-Si alloys joints. Mater Charact 144:205-218

2. Pickin CG, Young K (2006) Evaluation of cold metal transfer (CMT) process for welding aluminium alloy. Sci Technol Weld Join 11(5):583-585

3. Zhang H, Hu S, Wang Z, Liang Y (2015) The effect of welding speed on microstructures of cold metal transfer deposited AZ31 magnesium alloy clad. Mater Des 86:894-901
4. Wang P, Hu S, Shen J, Liang Y (2017) Characterization the contribution and limitation of the characteristic processing parameters in cold metal transfer deposition of an Al alloy. J Mater Process Technol 245:122-133

5. Cao R, Huang Q, Chen JH, Wang P-C (2014) Cold metal transfer spot plug welding of AA6061-T6-to-galvanized steel for automotive applications. J Alloys Compd 585:622-632

6. Nie Y, Zhang P, Wu X, Li G, Yan H, Yu Z (2018) Rapid prototyping of 4043 Al-alloy parts by cold metal transfer. Sci Technol Weld Join 23(6):527-535

7. Guojin L et al (2018) Gap bridging of 6061 aluminum alloy joints welded by variable-polarity cold metal transfer. J Mater Process Technol 255:927-935

8. Cong B, Ouyang R, Qi B, Ding J (2016) Influence of cold metal transfer process and its heat input on weld bead geometry and porosity of aluminum-copper alloy welds. Rare Met Mater Eng 45(3):606-611

9. Zhang C, Li Y, Gao M, Zeng X (2018) Wire arc additive manufacturing of Al-6Mg alloy using variable polarity cold metal transfer arc as power source. Mater Sci Eng A 711:415-423

10. Wang P, Hu S, Shen J, Liang Y, Pang J (2016) Effects of electrode positive/negative ratio on microstructure and mechanical properties of $\mathrm{Mg} / \mathrm{Al}$ dissimilar variable polarity cold metal transfer welded joints. Mater Sci Eng A 652:127-135

11. Kang MS, Chung H (2018) Dynamic force balance model considering tapering effect in gas metal arc welding. J Mater Process Technol 257:79-87

12. Chen M, Zhang D, Wu C (2017) Current waveform effects on CMT welding of mild steel. J Mater Process Technol 243:395-404

13. Alfaro SCA, Vargas JAR, de Carvalho GC, de Souza GG (2015) Characterization of 'humping' in the GTA welding process using infrared images. J Mater Process Technol 223:216-224

14. Liu H, Yang S, Xie C, Zhang Q, Cao Y (2018) Mechanisms of fatigue crack initiation and propagation in 6005A CMT welded joint. J Alloys Compd 741:188-196

15. Frost NE, Philips CE (1956) Studies in the formation and propagation of cracks in fatigue specimens. In: Proceedings of the International Conference on Fatigue of Metals, pp 520-526

Publisher's note Springer Nature remains neutral with regard to jurisdictional claims in published maps and institutional affiliations. 